\title{
Gingival bleeding and oral hygiene in women with von Willebrand Disease (VWD): a pilot study
}

Stefanie VanDuine, Karen Ridley, Jill Bashutski, Mark Snyder, Corey Powell, Susan Taichman

Introduction: Von Willebrand disease (VWD) is the most common hereditary coagulation abnormality. Individuals with VWD experience increased mucosal bleeding as well as gingival bleeding. Some evidence suggests that gingival bleeding is related to poor oral hygiene for fear of plaque removal methods that may cause bleeding to the gingival tissue. No studies have shown a correlation between VWD and gingival bleeding; however, these studies have not adjusted for possible confounding factors, such as presence of dental plaque, dental care utilisation, and oral hygiene habits.

Aims: To determine the relationship between von Willebrand factor (VWF) levels and the amount of gingival bleeding, when controlling for possible confounding variables.

Methods: This multi-site study included 44 women with VWD who completed a questionnaire to evaluate demographics, oral hygiene habits, perception of own

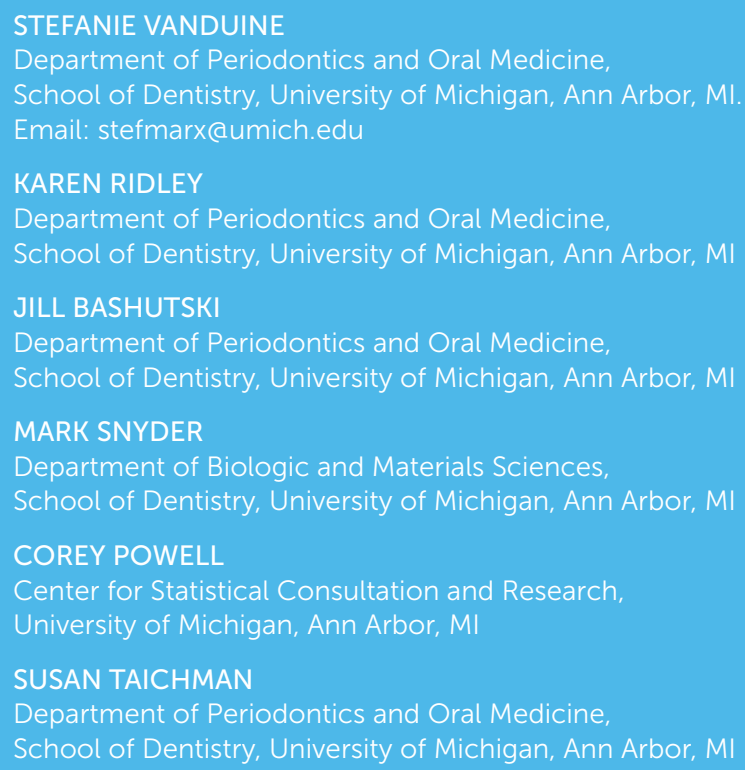

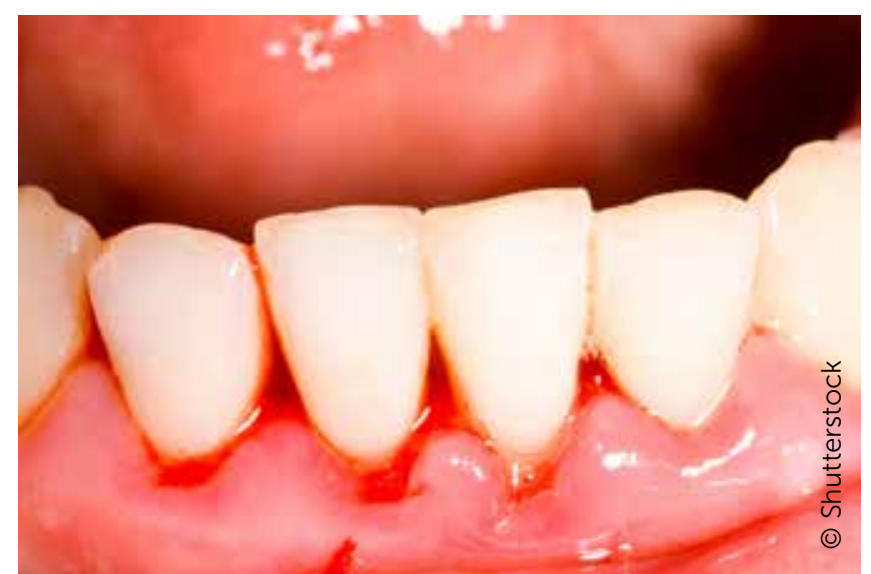

oral health, oral health quality of life, and dental care utilisation. Clinical dental examinations were conducted to determine the presence of plaque and gingival bleeding on six teeth in each individual. Von Willebrand disease type and severity were determined through a medical chart review. Institutional review board (IRB) approval was obtained prior to data collection. Results: Paired sample t-tests revealed that VWF levels did not significantly affect the amount of gingival bleeding noted ( $p>0.05$ ) when controlling for presence of plaque. Multiple linear regression models revealed that other factors, such as age and last dental visit $(p=0.044)$, had a larger effect on the amount of gingival bleeding.

Conclusion: In women with VWD, the presence of plaque and dental care utilisation determines gingival bleeding more than the severity of VWD.

Keywords: von Willebrand Disease, gingival bleeding, gingiva, von Willebrand factor, oral hygiene 
V on Willebrand disease (VWD) is the most common hereditary coagulation abnormality, presenting in an estimated $1 \%$ of the population ${ }^{[1-6]}$. In those with VWD, there is a deficiency or dysfunction of von Willebrand factor (VWF), a plasma protein that controls platelet haemostatic function and stabilises blood clotting with factor VIII (FVIII). Those with VWD often experience symptoms related to mucosal bleeding, with VWF levels greatly affecting the amount of bleeding experienced. Symptoms include epistaxis, gingival bleeding, menorrhagia and easy bruising. Women tend to have more intense symptoms than men, mostly relating to their menstrual cycle ${ }^{[1-7]}$.

Gingival bleeding is often reported in those with VWD, but recent efforts have been made to determine whether gingival bleeding is a true symptom and result of VWD. Studies examining the relationship between VWD and gingival bleeding have conflicting results; however, this may be due to indirect effects of VWD on confounding factors such as oral hygiene. For example, a study by Urdaneta and colleagues found that those with VWD had significantly more plaque and poorer oral hygiene than those without VWD ${ }^{[3]}$.

Research has shown that many patients with bleeding disorders have a fear of performing tasks that may increase bleeding, such as removing plaque with brushing and flossing. Consequently, it has been reported that patients with bleeding disorders generally have poorer oral hygiene than those without bleeding disorders ${ }^{[3]}$. Research has also shown a relationship between the presence of plaque and a higher risk for dental caries (cavities) and periodontal (gum) disease ${ }^{\text {8-12]. }}$. Therefore, if those with VWD are not properly removing plaque due to fear of causing gingival bleeding, they are putting themselves at a higher risk of developing dental caries and periodontal disease.

Dental caries in permanent teeth is the most prevalent disease worldwide. The presence of dental plaque on the tooth is necessary for a cavity to form ${ }^{[9]}$. When carious lesions (cavities) are not addressed, there is potential for the lesion to extend deep into the nerve of the tooth, causing a systemic infection and/ or causing the need for an extensive restoration or removal of the tooth itself.

Under the umbrella of periodontal diseases, gingivitis and periodontitis are the most prevalent diseases of the periodontium, the soft and hard tissues that surround the tooth. Alarming data from the National Health and Nutrition Examination Survey (NHANES) shows that $47.2 \%$ of American adults have periodontitis and even more American adults have gingivitis ${ }^{[8]}$. Gingivitis and periodontitis are caused primarily by the presence of bacterial plaque and bleeding is often the first sign of periodontal disease. ${ }^{\text {[9-13] }}$

Gingivitis is typically characterised as bleeding, redness and swelling of the gingiva. When gingivitis progresses into the other supporting structures of the periodontium, periodontitis occurs, causing destruction of the bone that surrounds the teeth and leading to mobility and eventual tooth loss. Though this process typically takes years to cause tooth loss, it is typically related to the amount of plaque present on the tooth surface ${ }^{[9-13]}$. Other factors, such as age, social habits, medical conditions, medications and genetic factors also play a role ${ }^{[8]}$. Scientific evidence shows a correlation between periodontal disease and systemic conditions such as heart disease, stroke and diabetes ${ }^{[9-13]}$.

In addition, those with VWD (along with other bleeding disorders) are at higher risk for severe treatment complications, especially after dental treatments such as extractions and local anaesthesia ${ }^{[14-16]}$. Patients with VWD therefore require dental treatment accommodations. However, this bleeding disorder is unfamiliar to many oral health care providers and many do not have experience in treating patients with coagulation disorders, especially VWD $[3,14,16,17]$

Due to the increased risk of treatment complications in VWD patients, preventive dentistry and oral health education is of great importance in order to minimise the need for extensive dental procedures. Efforts are being made to address this issue in the US. For example, in the United States some bleeding disorder clinics have a dental hygienist available during the clinic appointment to review oral health education with those with VWD and their oral healthcare providers, enabling the safe and effective treatment of these patients $[3,14,16,17]$ In the state of Michigan the majority have a DH as an active member of the hematology team. One of the early signs of periodontal disease is bleeding gums; thus, monitoring for gingival bleeding can be helpful in detecting and treating oral disease in its early stages. However, patients with VWD may have excessive gingival bleeding due to the lack of VWF. In order to implement preventive oral health measures in this patient population effectively, it is therefore important to first understand the effect of VWD on gingival bleeding.

The purpose of this cross-sectional pilot study was to determine the relationship between VWF levels and gingival bleeding when controlling for 
possible confounding variables, including age, plaque, oral hygiene habits and dental care utilisation. By understanding the relationship between VWD and gingival bleeding, providers will be able to better address oral hygiene as a preventive agent for periodontal disease. In addition, the study sought to determine the effectiveness of having a dental hygienist at bleeding disorder clinics to provide oral health education.

\section{Materials and methods}

Women aged 18 or older with VWD were eligible to participate in the study if they had at least 12 teeth present and were capable of providing informed consent. The study focused on women because of the detrimental effects that VWD has on women related to menstrual bleeding ${ }^{[7]}$. Exclusion criteria comprised those with uncontrolled diabetes, significant psychiatric illness that would interfere with the completion of the survey, or taking medications that cause gingival enlargement (eg calcium channel blockers, anti-seizure medications and immunosuppressants).

\section{Variables and instruments used}

Informed consent was documented prior to any data collection. After reading and signing the informed consent document, a 34-question survey was given to the participant to fill out. The survey asked questions about demographics, social behaviours, how often oral hygiene is reviewed at the individual's bleeding disorder clinic appointment, perception of oral health, oral hygiene habits, dental care utilisation, and potential issues around access to dental care.

A clinical oral examination was performed to assess the amount of plaque and gingival bleeding. Data was gathered on the six Ramfjord teeth - designated teeth that are likely to give a good representation of the entire mouth for data collection purposes (teeth numbers $3,9,12,19,25$, and 28) ${ }^{[18]}$. Presence of plaque was documented as 1 , and no plaque was documented as 0 . The gingival bleeding index was used to detect gingival bleeding on the six Ramfjord teeth ${ }^{[18]}$. This was assessed by employing a gentle C-wrap floss technique subgingivally, then assessing the presence or absence of bleeding. Absence of gingival bleeding was recorded as 0 , and the presence of gingival bleeding was recorded as 1. Data was collected on 12 surfaces, with a total of two surfaces per tooth.

Information from the patient's medical chart recording the patient's most recent VWF levels and date, treatment for VWD, other medical conditions and other medications was also gathered.

\section{Sample size estimation}

The study was designed to achieve at least a $45 \%$ difference in the occurrence of gingival bleeding when plaque is present in the twelve sites measured for the study. A power calculation was generated. Based on a study by Pizzo et al., it was determined that a sample size of 38 women would provide for at least $80 \%$ power that there would be a $45 \%$ or greater incidence of gingival bleeding when plaque is present ${ }^{[19]}$.

\section{Statistical Analysis}

All statistical analyses were performed using the Statistical Package for Social Sciences (SPSS) program, version 19.0 for Windows. Paired samples t-tests, logistic regression and multiple linear regression models were used to analyse the data gathered. All results were considered significant for a level of $\alpha<0.05$.

\section{Results}

\section{Descriptive statistics}

A total of 44 women with VWD who met all the eligibility criteria completed the study. The majority were between the ages of 18 and 30, Caucasian, unemployed and had dental insurance. The average age was $39.1+/-15.8$. The majority were non-smokers and used alcohol. Most participants had an education level of high school and/or some college. The descriptive characteristics of the 44 women subjects in the study are shown in Table 1.

The majority of participants attend the bleeding disorder clinic at Michigan State University. 65\% stated that oral hygiene is reviewed at their bleeding disorder clinic appointments frequently or at every visit. Only $15 \%$ of individuals stated that oral hygiene was never reviewed at these appointments. This was not specific to the clinic in which the individual attended. Of those surveyed, $57.5 \%$ stated that a dental hygienist at their bleeding disorder clinic is the primary provider that reviews oral hygiene education (data not shown).

Data regarding perception of oral health, selfreported gingival bleeding and oral hygiene habits is shown in Table 2. Although $73.8 \%$ of the women surveyed have dental insurance, only $56.1 \%$ had attended a dental appointment within the last six months. For $29.3 \%$ of women, it had been more than a year since their last appointment with a dentist. Open-ended questions were used to assess whether potential issues around access to dental care existed. The responses to these questions can be found in Table 3. 
Table 1: Demographics of sample

\begin{tabular}{|c|c|c|}
\hline & & TAGE \\
\hline & $\mathbf{N}$ & $(\%)$ \\
\hline $18-30$ & 18 & 40.9 \\
\hline $31-50$ & 14 & 31.8 \\
\hline $51-70$ & 12 & 27.3 \\
\hline Race & & \\
\hline Caucasian & 34 & 77.3 \\
\hline African American & 4 & 9.1 \\
\hline Asian & 0 & - \\
\hline Hispanic & 2 & 4.5 \\
\hline Other & 2 & 4.5 \\
\hline Refused & 2 & 4.5 \\
\hline Education & & \\
\hline Less than high school & 0 & - \\
\hline $\begin{array}{l}\text { High school and/or some } \\
\text { college }\end{array}$ & 22 & 50.0 \\
\hline College degree & 21 & 47.7 \\
\hline Refused & 1 & 2.3 \\
\hline Employment & & \\
\hline None & 22 & 50.0 \\
\hline Part-Time & 4 & 9.1 \\
\hline Full-Time & 17 & 38.6 \\
\hline Refused & 1 & 2.3 \\
\hline Dental Insurance & & \\
\hline Yes & 32 & 72.7 \\
\hline No & 11 & 25.0 \\
\hline Refused & 1 & 2.3 \\
\hline Alcohol Use & & \\
\hline Yes & 27 & 61.9 \\
\hline No & 16 & 36.4 \\
\hline Refused & 1 & 2.3 \\
\hline Tobacco Use & & \\
\hline Yes & 2 & 4.5 \\
\hline No & 40 & 90.9 \\
\hline Refused & 2 & 4.5 \\
\hline Bleeding Disorder Treatm & & \\
\hline University of Michigan & 20 & 45.5 \\
\hline Michigan State University & 24 & 54.5 \\
\hline
\end{tabular}

For data analysis purposes, the patients' VWD severity was classified into three groups, according to their most recent VWF reading, as follows: $1=$ VWF less than or equal to $30 ; 2=V W F 31-60 ; 3=V W F$ higher than 60 . Of the women who participated in the study, $16.3 \%$ had a VWF level of less than or equal to $30,14 \%$ had a VWF level between 31 and 60, and 53.5\% had a VWF level of more than 60. Although a VWF level of greater than 60 is considered to be at the lower end of normal,
Table 2: Perception of oral health, importance of oral health, frequency of gingival bleeding and oral hygiene habits

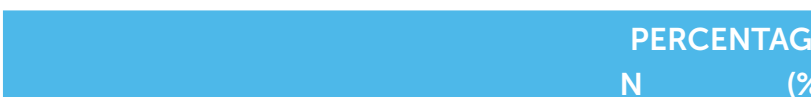

N

Gingival health condition

\begin{tabular}{l|r|r}
\hline Poor & 1 & 2.3 \\
\hline Fair - good & 31 & 70.5 \\
\hline Very good - excellent & 11 & 25.0 \\
\hline Refused & 1 & 2.3 \\
\hline
\end{tabular}

Dental health condition

\begin{tabular}{l|r|r}
\hline Poor & 3 & 6.8 \\
\hline Fair - good & 32 & 72.7 \\
\hline Very good - excellent & 8 & 18.2 \\
\hline Refused & 1 & 2.3
\end{tabular}

\section{Importance of oral health}

\begin{tabular}{l|r|r|} 
Very important & 36 & 81.8 \\
\hline Somewhat important & 7 & 15.9 \\
\hline Not at all important & 0 & 0 \\
\hline Refused & 1 & 2.3 \\
\hline
\end{tabular}

Gum bleed

\begin{tabular}{|l|r|r} 
More than twice a month & 20 & 45.5 \\
\hline
\end{tabular}

\begin{tabular}{l|l|l|}
\hline $1-2$ times per month & 10 & 22.7 \\
\hline
\end{tabular}

\begin{tabular}{|l|r|r}
\hline Less than once a month & 11 & 27.5 \\
\hline
\end{tabular}

\begin{tabular}{l|l|l} 
Refused & 3 & 6.8 \\
\hline
\end{tabular}

Bleeding with brushing

\begin{tabular}{l|r|r} 
Never & 2 & 4.5 \\
\hline Hardly ever - on occasion & 25 & 36.4 \\
\hline Fairly often - very often & 16 & 56.8 \\
\hline Refused & 1 & 2.3 \\
\hline
\end{tabular}

Bleeding with flossing

\begin{tabular}{l|r|r} 
Never & 4 & 9.1 \\
\hline Hardly ever - on occasion & 17 & 38.6 \\
\hline Fairly often - very often & 18 & 40.9 \\
\hline Refused & 5 & 11.4
\end{tabular}

\section{Frequency of brushing}

Less than once a day

Once a day

\begin{tabular}{r|r}
\hline 2 & 4.5 \\
\hline 7 & 15.9 \\
\hline 31 & 70.5 \\
\hline 4 & 9.1 \\
\hline
\end{tabular}

Refused

Frequency of flossing

Less than once a week

1 - 6 times per week

At least once per day

\begin{tabular}{|r|r|}
\hline 12 & 27.3 \\
\hline 14 & 31.8 \\
\hline 14 & 31.8 \\
\hline 4 & 9.1 \\
\hline
\end{tabular}

Refused

as previously stated, VWF levels can fluctuate in times of stress, exercise and hormonal changes. Data were missing on five individuals as lab values for VWF were not present in their medical charts. 
Table 3: Possible complications interfering with access to dental care for women with von Willebrand disease (VWD)

\begin{tabular}{|c|c|c|}
\hline QUESTION & PERCENTAGES (\%) & RESPONSES \\
\hline Have you ever avoided seeing a dentist? & $\begin{array}{l}\text { Yes }-38.6 \\
\text { Financial }-55.6 \\
\text { Anxiety }-44.4 \\
\text { No }-59.1 \\
\text { Refused }-2.3\end{array}$ & $\begin{array}{l}\text { "No insurance" } \\
\text { "Anxiety, fear, afraid, pain" } \\
\text { "I was told I bleed a lot" } \\
\text { "Dislike the dentist" } \\
\text { "It's not fun finding someone you trust" } \\
\text { "Not feeling comfortable with their knowledge of my } \\
\text { bleeding disorder" }\end{array}$ \\
\hline $\begin{array}{l}\text { Has an oral health care provider ever } \\
\text { refused you treatment because of } \\
\text { the possibility of bleeding disorder } \\
\text { complications? }\end{array}$ & $\begin{array}{l}\text { Yes }-13.6 \\
\text { No }-84.1 \\
\text { Refused }-2.3\end{array}$ & $\begin{array}{l}\text { "Because of high danger of bleeding" } \\
\text { "I have been sent away many times just for a basic } \\
\text { cleaning" } \\
\text { "It was tough at first to find a dentist who wasn't } \\
\text { nervous about liability of a BD when I was a kid" } \\
\text { "Refused to see [me] because I had a blood disorder" } \\
\text { "My bleeding time was } 15 \text { minutes" }\end{array}$ \\
\hline $\begin{array}{l}\text { Have you ever felt any bias from an oral } \\
\text { healthcare provider that you thought } \\
\text { was due to your bleeding disorder? }\end{array}$ & $\begin{array}{l}\text { Yes }-9.1 \\
\text { No }-79.5 \\
\text { Refused }-11.4\end{array}$ & $\begin{array}{l}\text { "High bleeding risk" } \\
\text { "Not willing to treat me" } \\
\text { "It was tough at first to find a dentist who wasn't } \\
\text { nervous about the liability of a BD when I was a kid" } \\
\text { "Complains about all the blood" }\end{array}$ \\
\hline
\end{tabular}

\section{Clinical measures}

On average, women had $7.34(S D=4.46)$ sites of plaque and $2.41(S D=2.55)$ sites of bleeding out of a possible 12 sites. The clinical data is shown in Table 4. When the data was stratified by VWF levels, it was also found that those with lower levels of VWF have less plaque and less gingival bleeding than those with closer to normal VWF levels. A visual representation of this data is shown in Figures 1 and 2.

To determine the relationship between plaque and gingival bleeding, each site in the mouth had one of four possible outcomes, as follows:

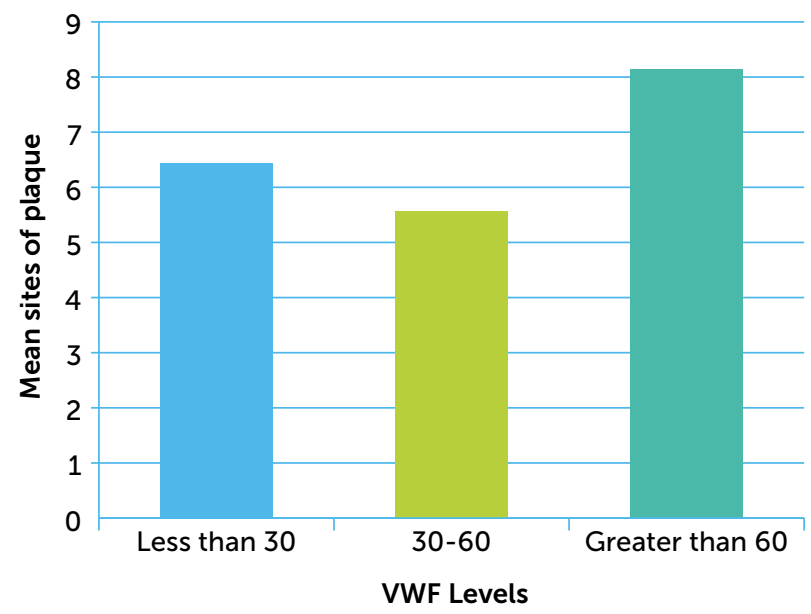

Figure 1: Average number of sites (of 12 measured sites) with plaque, stratified by VWF level
Bleeding

\begin{tabular}{|c|c|c|c|}
\hline \multirow{3}{*}{ Plaque } & & Yes & No \\
\hline & Yes & YPYB & YPNB \\
\hline & No & NPYB & NPNB \\
\hline
\end{tabular}

On average, $44.33 \%(n=5.32)$ of the 12 sites had plaque, but no bleeding; $35.58 \%(n=4.27)$ of the 12 sites had no plaque and no bleeding; $16.25 \%(n=1.95)$ of the 12 sites had plaque with bleeding; and only $3.75 \%$ $(n=0.45)$ of the 12 sites had no plaque with bleeding (see Table 5).

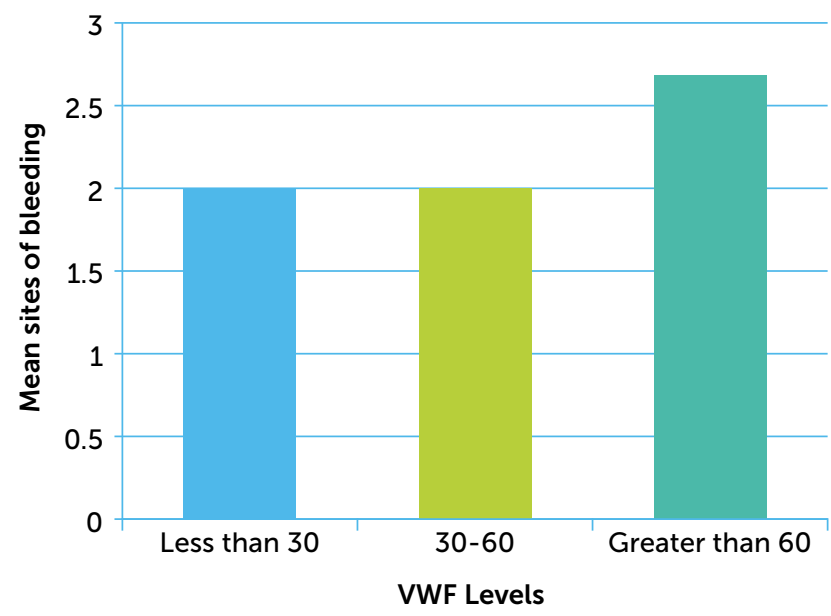

Figure 2: Average number of sites (of 12 measured sites) with plaque, stratified by VWF level 
Table 4: Frequency table: number of sites with plaque and bleeding of 12 sites measured per person

\begin{tabular}{|c|c|c|}
\hline \multicolumn{3}{|c|}{ NUMBER OF SITES } \\
\hline WITH PLAQUE & FREQUENCY & PERCENTAGE (\%) \\
\hline $0-4$ & 12 & 27.4 \\
\hline $5-8$ & 7 & 15.9 \\
\hline $9-12$ & 25 & 56.8 \\
\hline
\end{tabular}

NUMBER OF SITES

WITH BLEEDING FREQUENCY PERCENTAGE (\%)

\begin{tabular}{l|l|l}
\hline $0-4$ & 34 & 77.3 \\
\hline $5-8$ & 9 & 20.5 \\
\hline $9-12$ & 1 & 2.3 \\
\hline
\end{tabular}

When examining the effects of plaque on gingival bleeding, two main questions were tested with data analysis. Firstly, the number of sites that had plaque with bleeding (YPYB) was compared to the number of sites that had bleeding but no presence of plaque (NPYB). This answered the question "When bleeding was noted, is the bleeding more related to the presence of plaque or not?" Secondly, the number of sites that had plaque with bleeding (YPYB) was compared to the number of sites that had plaque with no bleeding (YPNB). Comparing these two measures provided the answer to the question "When plaque was present, is the site likely to have gingival bleeding or not?"

Statistically significant differences were noted between the mean differences in YPYB vs. NPYB and YPYB vs. YPNB groups when assessed using paired sample t-tests $(p<0.001)$, (see Table 6$)$. This shows that when there is plaque present on a surface, it is more likely not to bleed when using the gentle C-wrap flossing technique. Though studies have shown the relationship between plaque and gingival bleeding, low amounts of gingival bleeding were noted when using the C-wrap technique in this group, even with the presence of plaque. The second test shows that when gingival
Table 5: Average number of sites (of 12 sites measured) and standard deviations for each possible clinical outcome ( $\mathrm{Y}=$ Yes, $\mathrm{N}=$ No, $\mathrm{P}=$ Plaque, $\mathrm{B}=$ Bleeding)

\begin{tabular}{l|l|l}
\multicolumn{1}{c}{ MEAN } & \multicolumn{1}{l}{ SD } \\
\hline YPYB & 1.95 & 2.27 \\
\hline YPNB & 5.32 & 4.36 \\
\hline NPYB & 0.45 & 0.76 \\
\hline NPNB & 4.27 & 4.31 \\
\hline
\end{tabular}

bleeding is noted, it is more likely due to the presence of plaque. Linear regression was used to determine whether VWF level had a significant effect on the relationship noted. In both tests, VWF was not a statistically significant confounding variable ( $p>0.05$ ), as shown in Table 6.

As an inverse relationship was noted, in that those with closer to normal VWF levels presented with more gingival bleeding, multiple linear regression was used to test for possible confounding variables. In the model shown in Table 7, age is shown to have a protective effect on the number of sites with gingival bleeding. Time since last dental visit also had a significant effect on the relationship, showing that when an individual does not visit the dentist every six months, the average number of sites with gingival bleeding increases significantly $(p=0.044)$

Since plaque had a larger effect on gingival bleeding than VWF, the effectiveness of providing oral health education was analysed. Linear regression was used to determine whether the frequency of oral health education played a role in the amount of plaque noted. For those who stated that they never received oral health education at their bleeding disorder clinic, plaque was present on 10.5 of the 12 sites measured. In those women who stated that oral hygiene education was reviewed at every visit, plaque was present on 6.8 of the 12 surfaces measured. This difference in the amount of plaque was statistically significant $(p=0.03)$, as seen in Figure 3.

Table 6: Difference in means between possible outcome pairs, with significance for paired samples t-test and when using linear regression to control for VWF level

\begin{tabular}{l|l|l|l}
\cline { 2 - 3 } & \multicolumn{2}{c}{$\begin{array}{l}\text { P-VALUE WHEN } \\
\text { COMPARING MEANS }\end{array}$} & $\begin{array}{l}\text { P-VALUE WHEN CONTROLLING } \\
\text { FOR VWF LEVEL }\end{array}$ \\
\hline YPYB v YPNB & 3.47 & $<0.01$ & 0.82 \\
\hline YPYB v NPYB & 1.56 & $<0.01$ & 0.45 \\
\hline YPNB v NPYB & 5.02 & $<0.01$ & 0.53 \\
\hline NPNB v NPYB & 3.74 & $<0.01$ & 0.23 \\
\hline YPYB v NPNB & 3.47 & $<0.01$ & 0.22 \\
\hline YPNB v NPNB & 1.28 & 0.41 & 0.33 \\
\hline
\end{tabular}




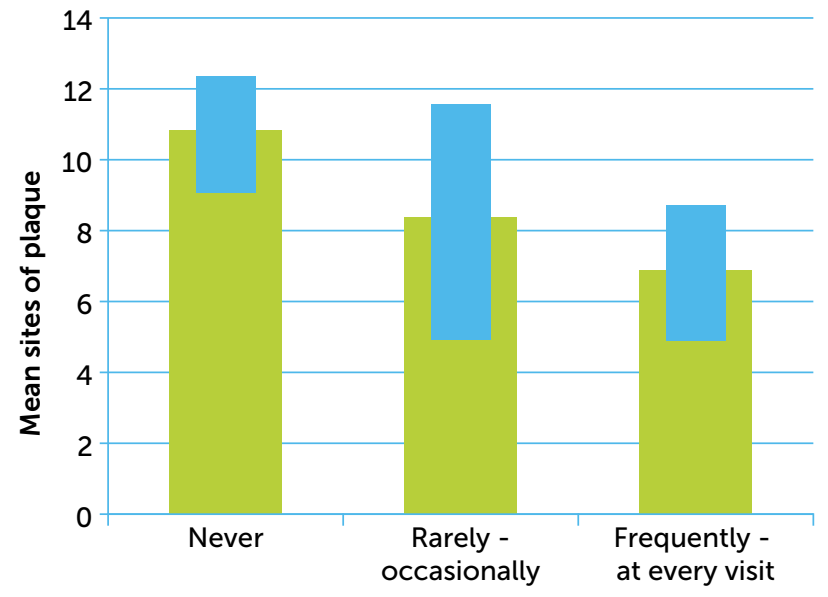

Frequency of receiving oral health education

Figure 3: Percentage of sites with plaque present, according to how frequently oral health education is reviewed at the bleeding disorder treatment centre $(p=0.031)$ (error bars represent $95 \% \mathrm{Cl}$ )

\section{Discussion and conclusion}

To the authors' knowledge, this was the first study to assess the relationship between VWF levels, plaque accumulation and gingival bleeding when controlling for other possible confounding variables. Previous studies have compared plaque presence and gingival bleeding in healthy individuals to those with VWD, but none have controlled for varying VWF levels or used plaque as a confounding variable for gingival bleeding ${ }^{[3,14,15,22]}$. This study sought to assess whether gingival bleeding was related to plaque even while controlling for possible confounding variables such as VWF levels, oral hygiene habits, demographics, access to dental care, and self-reported gingival bleeding.
For this particular study, severity of VWD was controlled for in the analysis to determine whether there was a trend between more bleeding sites and decreased VWF. The relationship between VWF level and gingival bleeding sites was first tested with linear regression. This relationship was not significant, prompting the need to test confounding variables. Age and last dental appointment seemed to have a greater effect on the amount of gingival bleeding noted in each patient. Though not a statistically significant relationship, the amount of gingival bleeding decreased as age increased. Having a dental visit within the past six months had a protective effect on the amount of bleeding.

Comparison and analysis of the means of these four outcomes indicated that the presence of plaque may be more significant in causing gingival bleeding than low VWF. In fact, the majority of sites in the population involved in the study had plaque presence, but no concomitant bleeding. This study shows that there is $95 \%$ confidence that among women with VWD, the average number of sites with gingival bleeding is between 1.60 and 3.19 of 12 sites measured. The fact that a greater number of sites had no bleeding, even with presence of plaque, indicates that women with VWD can perform gentle C-wrap flossing without causing gingival bleeding, suggesting that performing normal oral hygiene interventions would not adversely affect their bleeding control. Expressing this confidently to patients with VWD can assure them that it is possible to perform proper oral hygiene effectively without causing excessive, if any, gingival bleeding.

When examining the amount of gingival bleeding and determining confounding variables related to delivering oral hygiene instruction, two questions on

Table 7; Multiple linear regression model for bleeding in women with VWD. Dependent variable: gingival bleeding

\begin{tabular}{l|l|l|l|l}
\multicolumn{5}{c}{$\begin{array}{l}\text { MEAN NUMBER OF SITES WITH BLEEDING* } \\
\text { COEFFICIENT }\end{array}$} \\
$\begin{array}{l}\text { INDEPENDENT VARIABLES } \\
\text { ESTIMATE }\end{array}$ & STD ERROR & P-VALUE & 95\% CI \\
VWF level & Ref & Ref & Ref & Ref \\
\hline Less than 30 & 0.367 & 1.145 & 0.750 & $(-1.953,2.686)$ \\
\hline $30-60$ & 0.349 & 0.891 & 0.698 & $(-1.457,2.155)$ \\
\hline Greater than 60 & -0.285 & 0.256 & 0.273 & $(-0.804,0.234)$ \\
\hline Age & & & & Ref \\
\hline Last visit to dentist & Ref & Ref & 0.044 & $(0.051,3.363)$ \\
\hline Less than 6 months ago & 1.707 & 0.817 & & \\
\hline More than 6 months ago & & &
\end{tabular}

Data shown as mean \pm SE $(95 \% \mathrm{Cl})$

*Of 12 sites measured 
Table 8: Chi-square test for gingivitis in women from NHANES and women with VWD

\begin{tabular}{l|l|l}
\multicolumn{2}{c}{} & NUMBER (PERCENT (\%)) GINGIVITIS \\
\hline Study & Yes & No \\
\hline NHANES & 1996 & 2173 \\
& $(47.9)$ & $(52.1)$ \\
\hline VWD & 20 & 16 \\
& $(55.6)$ & $(44.6)$ \\
\hline
\end{tabular}

Cases weighted by $\mathrm{N}$

Pearson's Correlation: 0.169

the patient survey were examined. The first asked, "How often does someone at your bleeding disorder clinic discuss oral health with you?"; the second asked, "Who usually discusses the importance of oral health with you?" Both variables were used to analyse the effectiveness of having a dental hygienist at bleeding disorder clinics. Results showed that there is a significant difference in both presence of plaque and gingival bleeding when controlling for these two variables. This may imply that educating patients on oral health can result in improved oral hygiene, leading to a decreased risk of developing periodontal disease. As previously stated, other confounding factors influence the development of periodontal disease as well, including, but not limited to medication, genetics, and age.

There were several limitations to the study, mostly related to limited time and resources. A longitudinal study would have been beneficial to evaluate the effects of the fluctuation of VWF levels over time ${ }^{[16,20]}$. A larger sample size would have given the study more power.

One major limitation was the lack of a true control group. In the hope of addressing this, data from the study was compared with data from the National Health and Nutrition Examination Survey (NHANES) to determine whether the presence of gingivitis differed in women with and without VWD ${ }^{[21]}$. A chi-square test was used to compare the presence of gingivitis in women with VWD and the presence of gingivitis in women from the NHANES data. When cases were weighted by $\mathrm{N}$, the difference in the percentages was not significant (Pearson's Correlation: 0.169), as shown in Table 8.

Another limitation was the index used to measure presence of plaque. As the results showed that plaque was present on the majority of sites with no bleeding noted, an index measuring the amount of plaque present would have been beneficial in order to give insight into how long the plaque was present, contributing to its thickness.

\section{Conclusion}

In summary, this study found that VWF levels do not have a significant effect on the amount of gingival bleeding present, but that gingival bleeding is more a result of poor oral hygiene and lack of dental care. Sharing this information with individuals that have VWD can help them understand that gingival bleeding is not due to the bleeding disorder itself, but from not properly removing plaque. It is imperative that the VWD population understand the aetiology of periodontal disease and that, rather than being the result of low VWF levels, gingival bleeding is a sign of periodontal disease.

The study also found that the inclusion of a dental hygienist in the comprehensive team at bleeding disorder clinic may lead to improved patient oral hygiene. Ultimately, as gingival bleeding in women with VWD has been shown to be minimal and related to the presence of plaque rather than being a direct result of low VWF levels, practicing routine oral hygiene is safe and recommended in this patient population. As many women with VWD have felt bias or have been refused treatment by oral healthcare providers, the dental hygienist serves as an important liaison between the patient, the dentist and the bleeding disorder clinic. In addition, the hygienist communicates with the haematologist, explaining dental procedures so that appropriate medical recommendations can be made, thereby reducing the incidence of dental treatment complications. Improving oral care and decreasing gingival inflammation can ultimately reduce the risk of oral systemic disease.

\section{Acknowledgments}

S. VanDuine, K. Ridley, and LS. Taichman designed the research. S. VanDuine and K. Ridley collected data. S. VanDuine analysed data. C. Powell provided statistical guidance for data analysis. S. VanDuine drafted the manuscript. M. Snyder provided guidance on research design and interpretation. LS. Taichman, J. Bashutski, and K. Ridley provided editorial guidance. All authors collaborated and approved the final version of this manuscript

We thank the University of Michigan Hematology and Coagulation Disorders Clinic, Michigan State University Center for Bleeding and Clotting Disorders, and Michigan Center for Oral Health Research.

A Rackham Graduate School Research Grant supported this study. Authors declare no competing financial interests. The authors also state that they have no interests that may be perceived as posing a conflict or bias. 


\section{References:}

1. Nichols WL, Hultin MB, James AH, et al. von Willebrand disease (VWD): evidence-based diagnosis and management guidelines, the National Heart, Lung, and Blood Institute (NHLBI) Expert Panel report (USA). Haemophilia 2008; 14: 171-232.

2. Mannucci PM, Federici AB, James AH, Kessler CM. von Willebrand disease in the 21st century: current approaches and new challenges. Haemophilia 2009; 15: 1154-8.

3. Urdaneta MB, Urdaneta MB, Mendez VF, Socorro CB. Evaluating periodontal conditions in patients with von Willebrand's disease in Hospital Universitario de Maracaibo (University Hospital, Maracaibo)-Venezuela. Med Oral Patol Oral Cir Bucal 2008; 13: 303-6.

4. Hassan S, Qureshi W, Donthireddy V, Kuriakose P. Congenital von Willebrand's disease and clinical hypothyroidism. Haemophilia 2013; 19: 242-5.

5. Sadler JE. Von Willebrand disease type 1: a diagnosis in search of a disease. Blood 2003; 101(6):2089-93. Available from: http://www.bloodjournal.org/content/ bloodjournal/101/6/2089.full.pdf?sso-checked=true (accessed 9 January 2017)

6. Laffan M, Lester W, O'Donnell JS, et al. The diagnosis and management of von Willebrand disease: a United Kingdom Haemophilia Centre Doctors Organization guideline approved by the British Committee for Standards in Haemotology. $\mathrm{Br} \mathrm{J}$ Haematol 2014; 167: 453-65.

7. World Federation of Hemophilia. About bleeding disorder: von Willebrand disease, symptoms and diagnosis. May 2012. Available from: $h$ ttp://www.wfh.org/en/page. aspx?pid=676 (accessed 9 January 2017).

8. Eke PI, Dye BA, Wei L, Thornton-Evans GO, Genco RJ. Prevalence of periodontitis in adults in the United States: 2009 and 2010. J Dent Res 2012; 91(10): 914-20.

9. Löe $H$, Theilade $E$, Jensen $S B$. Experimental gingivitis in man. J Periodontol 1965 Feb;36(3):177-87. Available from http:// www.joponline.org/doi/10.1902/jop.1965.36.3.177 (accessed 9 January 2017).

10. Yaacob M, Worthington HV, Deacon SA, et al. Powered versus manual toothbrushing for oral health. Cochrane Database Syst Rev 2014; (6): CD002281. doi: 10.1002/14651858. CD002281.pub3. Available from http://onlinelibrary.wiley.
com/doi/10.1002/14651858.CD002281.pub3/full (accessed 9 January 2017)

11. Farina R, Tomasi C, Trombelli L. The bleeding site: a multi-level analysis of associated factors. J Clin Periodontol 2013;40(8): 735-42. doi: 10.1111/jcpe.12118.

12. Trombelli L, Takatis DN, Scapoli C, et al. Modulation of clinical expression of plaque-induced gingivitis. J Clin Periodontol 2004; 31: 239-52.

13. Lang NP, Cumming BR, Löe $H$. Toothbrushing frequency as it relates to plaque development and gingival health. $J$ Periodontol 1973; 44: 396-405.

14. Ziebolz D, Stühmer C, Hornecker E, et al. Oral health in adult patients with congenital coagulation disorders--a case control study. Haemophilia. 2011; 17: 527-31.

15. Archer WH, Subrow HJ. Fatal hemorrhage following regional anesthesia for operative dentistry in a hemophilic. Oral Surg Oral Med Oral Pathol 1954; 7: 464-70.

16. Gupta A. Bleeding disorders of importance in dental care and related patient management. J Can Dent Assoc 2007; 73: 77-83.

17. Wallak MB. Periodontal therapy for a patient with von Willebrand's disease a case report. J Periodontol 1972; 43: 495-501.

18. Eberhard J, Grote K, Luchtefeld M, et al. Experimental gingivitis induces systemic inflammatory markers in young healthy individuals: a single-subject interventional study. PLoS One. 2013:8:e55265. doi: 10.1371/journal/pone.0055265. Available from http://journals.plos.org/plosone/article?id=10.1371/ journal.pone.0055265 (accessed 9 January 2017).

19. Pizzo G, Guiglia R, Licata ME, et al. Effect of hormone replacement therapy (HRT) on periodontal status of postmenopausal women. Med Sci Monit 2011; 17: PH23-7.

20. Chen YC, Yang L, Cheng SN, et al. von Willebrand disease: a clinical and laboratory study of sixty-five patients. Ann Hematol 2011; 90: 1183-90.

21. Taichman LS, Eklund SA. Oral contraceptives and periodontal diseases: rethinking the association based upon analysis of National Health and Nutrition Examination Survey data. J Periodontol 2005; 76: 1374-85.

22. Weickert L, Miesbach W, Alesci SR, Eickholz P, Nickles K. Is gingival bleeding a symptom of patients with type 1 von Willebrand disease? A case-control study. J Clin Periodontol 2014; 41(8): 766-71. doi: 10.1111/jcpe.12274.

\section{The Journal of Haemophilia Practice}

\section{An open-access journal for sharing experience in the care of people with bleeding disorders}

www.haemjournal.com 